\title{
Comment
}

\section{Co-ordinated aftercare for schizophrenia-A report of a pilot project}

\author{
R. G. McCreadie, Director, Department of Clinical Research, Crichton Royal Hospital, \\ Dumfries
}

It is probable that at any given time three quarters of known chronic schizophrenics are not in hospital, but are living in the community. Many such patients (and their relatives) need long-term support; the Salford project is an attempt to co-ordinate the care given to this group of patients by professionals in an inner city area. That co-ordination is indeed necessary in Salford is best shown by the relationship (or lack of it) between community psychiatric nurses and consultants. Each consultant has to deal with a number of CPNs, and each CPN with a number of consultants. Why the CPN service could not be more closely linked with the consultant-based service is not clear.

A full-time co-ordinator, funded by the DHSS for two years, was responsible for setting up the project, which had to be done with existing staff and resources. The main objective was to design and implement a multi-disciplinary case management system involving periodic assessment and review of treatment. Fortnightly meetings of interested professionals (psychiatrist, CPN, social worker, occupational therapist, psychologist) were held for one and a half hours. Referrals come mainly from team members, and 27 patients were under review at 12 months. This number was smaller than envisaged as more reviews were necessary. Each patient was assessed before the meeting, in the main by two professionals - one looking at medical aspects, the other at social aspects. The assessment was considered at the patient's review, and the first care plan drawn up; problems and needs were identified and action decided. The key worker was identified and a progress review carried out at six months.

The principal achievement of the pilot project was indeed a better co-ordination of existing types of care, especially with regard to monitoring and administering medication. Also relatives were consulted more often which led to a greater awareness of their needs.

However, as with most projects, more problems were identified than solved, and the list makes familiar and depressing reading to anyone involved in community care of the chronic schizophrenic: lack of sheltered accommodation, lack of staff with skills to do family work, lack of home carers (home helps with extra skills), insufficient staff able to provide regular long-term support for patients, and so on. Because such major problems were more clearly identified, there was some staff resistance to the project. The staff felt they were stretched as it was, and they questioned the point of identifying patients' needs when there were no resources to implement them.

The report thus raises wider issues. Even if a coordinated patient care system does exist, hardpressed staff (and patients' relatives), especially in inner city areas with few after-care resources, must view with trepidation the continuing and increasingly rapid run-down of in-patient facilities. Unless there is a great improvement in community facilities which pre-date the run-down of psychiatric hospitals, we shall be doing our patients a grave disservice. 